DOI: 10.4274/tpa.634

\title{
Lennox-Gastaut sendromlu hastaların klinik özellikleri ve uzun süreli seyri
}

\section{Clinical evaluation and long term prognosis of patients with Lennox-Gastaut syndrome}

\author{
Arzu Ekici, Coşkun Yarar, Ayten Yakut, Kürşat Bora Çarman, Sevgi Yimenicioğlu \\ Eskişehir Osmangazi Üniversitesi Tip Fakültesi, Çocuk Nörolojisi Bilim Dall, Eskişehir, Türkiye
}

\section{Özet}

Amaç: Bu çalışmanın amacı Eskişehir Osmangazi Üniversitesi Çocuk Nörolojisi Bilim Dalı'nda Lennox-Gastaut sendromu tanısı ile izlenen 20 hastanın klinik özellikleri, tedavi ve seyrinin geriye dönük olarak değerlendirilmesidir.

Gereç ve Yöntem: Lennox-Gastaut sendromu tanısı, birden fazla değişik nöbet tipi olması, elektroansefalogramda yaygın, yavaş (<3 Hz/sn) diken-dalga örüntüsünün bulunması, psikomotor gerilik olmasıyla konuldu. Etiolojik neden bulunamayan hastalar idiyopatik olarak tanımlandı. Hastaların doğum öncesi, doğum ve doğum sonrası risk etkenleri, nöbet ve klinik özellikleri, nöromotor gelişimleri, tedavi ve seyir özellikleri değerlendirildi.

Bulgular: Hastaların 13'ü erkek, yedisi kız, erkek/kız oranı 1,9 idi. On dokuz hastanın klinik belirtisi vardı. En sık saptanan risk etkeni hipoksik iskemik ansefalopatiydi. Yüzde altmış hastada infantil spazm öyküsü vardı.Tonik, tonik klonik ve atonik-drop atak en sık görülen nöbetler, konuşma bozukluğu ve mikrosefali ise en sık görülen nörolojik bulgulardı. Elektroansefalografide yaygın yavaş diken-dalga aktivitesi (1-3 $\mathrm{Hz} / \mathrm{sn}$ ) yanı sıra en sık bulgu biyoelektrik status epileptikus ve 9-14 Hz/sn hızlı aktivite deşarjlarıydı. En sık nörogörüntüleme bulgusu beyin atrofisiydi. Çoklu antiepileptik ilaç kullanımına rağmen hastaların \%60'ı günde çok sayıda nöbet geçiriyordu. En sık kullanılan antiepileptik ilaçlar sodyum valproat, klobazam, lamotrijin ve topiramattı.

Çıkarımlar: Lennox-Gastaut sendromunda gerek dirençli nöbetler gerekse zeka işlevlerinde bozulma nedeniyle seyir kötüdür. Çoklu antiepileptik ilaç kullanımına rağmen nöbet kontrolü sağlanamamaktadır. Yeni antiepileptik ilaçlara gereksinim duyulmaktadır. (Türk Ped Arş 2012; 47: 47-51) Anahtar sözcükler: Antiepileptik ilaçlar, dirençli nöbet, EEG, Lennox-Gastaut sendromu, seyir

\section{Summary}

Aim: The aim of this study was to retrospectively evaluate clinical features, treatment, prognosis of 20 patients followed up as Lennox-Gastaut Syndrome in Eskişehir Osmangazi University Pediatric Child Neurology department.

Material and Method: Multiple different types of seizure, diffuse spike-wave pattern $(<3 \mathrm{~Hz})$ on electroencephalogram, psychomotor retardation were the diagnostic criteria for Lennox-Gastaut Syndrome. The patients who had no etiologic reason were described as the idiopathic type. Prenatal, natal and postnatal risk factors, seizure and clinical features, neurodevelopmental status, treatment and prognostic features were evaluated.

Results: Thirteen patients were female, seven were male; male/female ratio was 1,9. Nineteen patients were described as the symptomatic type. Hypoxic ischemic encephalopthy was the most common risk factor. Sixty percent of the patients had a history of infantile spasms. Tonic and tonic clonic and atonic drop attack were the most common seizure types. Speech impairment and microcephaly were the most frequently seen neurologic findings. Diffuse spike-wave activity (1-3 Hz/s) on EEG, bioelectrical status epilepticus and 9-14 Hz/sn fast activity discharges were the most commonly seen discharges. The most common neuroimaging finding was cerebral atrophy. Sixty percent of the patients suffered from a large number of seizures per day despite multiple antiepileptic drugs. The most commonly used antiepileptic drugs were valproate sodium, clobazam, lamotrigine and topiramate.

Conclusions: The prognosis of Lennox-Gestaut Syndrome is poor due to either recurrent seizures or mental deterioration. Seizure control can not be provided despite the use of multiple anti-epileptic drugs. New antiepileptic drugs are needed. (Turk Arch Ped 2012; 47: 47-51)

Key words: Antiepileptic drugs, EEG, Lennox-Gastaut Syndrome, prognosis, refractory seizure

\section{Giriş}

Lennox-Gastaut Sendromu (LGS) çocukluk çağında görülen seyri kötü olan epileptik sendromdur (1). Çocukluk çağı epilepsilerinin \%3-10'unu oluşturmaktadır (2,3). Erken çocukluk döneminde başlayan birden fazla değişik tip nöbet, bilişsel işlevlerde bozulma ve elektroansefolografide (EEG) yaygın yavaş diken-dalga (1-3 Hz/sn) örüntüsü ile belirgindir (1).

Yazışma Adresi/Address for Correspondence: Dr. Arzu Ekici, Eskişehir Osmangazi Üniversitesi Tıp Fakültesi, Çocuk Nörolojisi Bilim Dalı, Eskişehir, Türkiye E-posta: drarzuekici@gmail.com Geliş Tarihi/Received: 08.06.2011 Kabul Tarihi/Accepted: 05.09.2011 Türk Pediatri Arşivi Dergisi, Galenos Yayınevi tarafından basılmıştır. / Turkish Archives of Pediatrics, published by Galenos Publishing 
Başlangıçta klasik klinik ve EEG bulgularının olmaması nedeniyle tanı koymak zordur (4). Olguların yaklaşık yarısında infantil spazm öyküsü vardır (5). Patojenezi tam olarak açıklığa kavuşmamış olmakla birlikte otoimmünitenin rolü olduğu düşünülmektedir (6). Lennox-Gastaut sendromu asfiksi, merkezi sinir sistemi enfeksiyonu (MSS), kafa travması, doğumsal enfeksiyon ve beyin malformasyonuna bağlı olarak görülebileceği gibi idiyopatik olarak da karşımıza çıkabilmektedir. Etiolojik neden saptanan olgularda seyir daha kötüdür $(5,7)$. Çoklu antiepileptik ilaç kullanılmasına karşın nöbetler çoğu kez kontrol altına alınamamaktadır. Gerek nöbetlerin kontrol edilememesi, gerekse zeka geriliği LGS seyrini olumsuz etkilemektedir (4).

Bu çalışmanın amacı Eskişehir Osmangazi Üniversitesi Tıp Fakültesi Çocuk Nörolojisi Bilim Dalı'nda LGS tanısı ile izlenen 20 hastanın klinik özellikleri, tedavi ve seyrinin geriye dönük olarak değerlendirilmesidir.

\section{Gereç ve Yöntem}

Bu çalışmada Eskişehir Osmangazi Üniversitesi Tıp Fakültesi Çocuk Nörolojisi Bilim Dalı'nda 1994-2010 yılları arasında LGS tanısı ile izlenen 20 hasta geriye dönük olarak değerlendirildi. Lennox-Gastaut sendromu tanı ölçütü olarak, birden fazla değişik nöbet tipi olması, EEG'de yaygın, yavaş (<3 $\mathrm{Hz} / \mathrm{sn}$ ) diken-dalga örüntüsünün bulunması, değişik derecelerde psikomotor gerilik olmasına göre konuldu. Herhangi bir risk etkeni bulunmayan, nöbet öncesi psikomotor gelişimi ve nörogörüntülemesi normal olan, etiolojik neden bulunamayan hastalar idiyopatik, diğerleri ise semptomatik LGS olarak tanımlandı. Düşük apgar skoru olan, doğumda canlandırma uygulanan ve mekanik ventilatöre bağlanan hastalar hipoksik iskemik ansefalopati $(\mathrm{HI} A)$ olarak değerlendirildi. Hastaların hepsinde doğum öncesi, doğum ve doğum sonrası risk etkeni, etiolojik neden, nöbet başlama yaşı, nöbet tipleri, nöbet sıklığı, nöromotor gelişimi, nörolojik muayene, EEG, kraniyal görüntüleme ve gerekli olanlarda metabolik testler yapıldı. Altı yaş altındaki hastaların psikososyal-motor gelişimleri Denver II Gelişimsel Tarama Testi, altı yaş üstündeki hastaların zeka değerlendirilmesi Stanford-Binet ya da Weschler Zeka Ölçeği ile değerlendirildi. Nöbet tipleri ailelerden alınan öykü, muayene ve EEG kaydı sırasındaki klinik gözlemlere göre belirlendi. Elektroansefalografi kayıtları Nihon Kohden Neurofax $7310 \mathrm{~F}$ EEG cihazı ile yapıldı. Hastaların uzun süreli izleniminde kullanılan antiepileptik ilaç (AEi) etkinliği, EEG bulguları ve gelişen komplikasyonlar değerlendirildi.

\section{Bulgular}

Yaşları 1,5-16 (ortalama 10,75) yıl arasında değişen 13'ü (\%65) erkek, yedisi (\%35) kız toplam 20 hasta geriye dönük olarak değerlendirildi. Hastaların izlem süresi ortalama 7,5 (113) yıldı. Nöbet başlama yaşı ortalama 14,6 (1 ay-3,5 yaș) ay, LGS tanı alma yaşı ise ortalama $4,5(1,5-5,5)$ yaş idi. Hastaların 17'sinde (\%85) LGS üç yaşından sonra gelişmişti. On dokuz (\%95) hasta semptomatik, bir (\%5) hasta ise idiyopatik LGS olarak tanımlandı.

En sık saptanan etiolojik neden HiA (\%65) idi. Diğer etiolojik nedenler ise üç (\%15) hastada kortikal displazi, bir (\%5) hastada MSS enfeksiyonu, bir (\%5) hastada yenidoğan sepsisi, bir (\%15) hastada ise kafa içine kanama idi. Hastaların ikisinde (\%10) düşük tehdidi, birinde (\%5) de intrauterin hidrosefali öyküsü vardı. Hastaların üçünde (\%15) ailede epilepsi, birinde (\%5) febril konvulziyon öyküsü vardı. Hastaların \%60'ında (12 hasta) infantil spazm öyküsü vardı. İnfantil spazm öyküsü olan 12 hastanın 10 'unun $(\% 83,3)$ günde çok sayıda nöbeti vardı ve LGS tanı alma yaşı 4,5 yaş idi.

Hastaların hepsi orta veya ağır derecede geri zekalı idi. Zeka ve motor gerilik nöbetleri daha geç başlayan ve nöbet öncesi nöromotor gelişimi normal olan hastalarda daha azdı. En sık görülen nörolojik bulgular konuşma bozukluğu (\%60) ve mikrosefali (\%35) idi (Tablo 1). Konuşma bozukluğu olan 12 (\%60) hastanın yedisinin (\%35) hiç anlamlı kelimesi yoktu, beşinde (\%25) ise fonasyon bozukluğu vardı. Beş (\%25) hastada spastisite vardı ve bir (\%5) hasta tekerlekli sandalye kullanıyordu. Dört (\%20) hasta yatağa bağımlıydı. Dört (\%20) hastada otistik bulgular, iki (\%10) hastada sinirlilik, bir (\%5) hastada hiperaktivite olmak üzere toplam yedi (\%35) hastada nöropsikiyatrik bulgular vardı. Nöropsikiyatrik bulguları olan hastaların tümünde infantil spazm öyküsü vardı. Otistik bulguları olan hastaların etiolojisinde ikisinde HİA, ikisinde kortikal displazi vardı.

Hastaların \%75'inde (15 hasta) ikiden fazla değişik nöbet, \%25'inde (5 hasta) iki tip nöbet vardı. En sık görülen nöbet tipi yaygın tonik (\%80) ve yaygın tonik-klonik (\%75) idi. Atonik-drop atak $12(\% 60)$, kısmi nöbet sekiz (\%40), atipik absans yedi (\%35), miyoklonik nöbet ise beş (\%25) hastada izlendi (Tablo 2). İzlem süresi boyunca üç (\%15) hastada konvülzif status epileptikus gelişti. Bir hastada iki kez tekrarladı. Hastaların

\begin{tabular}{|l|c|c|}
\hline \multicolumn{2}{|c|}{$\begin{array}{c}\text { Tablo 1. Lennox-Gastaut sendromlu hastaların nörolojik } \\
\text { bulguları (n=20) }\end{array}$} \\
\hline Bulgu* & Sayı & $\%$ \\
\hline Zeka geriliği & 20 & 100 \\
\hline Konuşma bozukluğu & 12 & 60 \\
\hline Mikrosefali & 7 & 35 \\
\hline Spastisite & 5 & 25 \\
\hline Hemiparezi & 4 & 0 \\
\hline Otistik bulgular & 4 & 20 \\
\hline Yutma güçlüğü & 3 & 15 \\
\hline Nistagmus & 2 & 10 \\
\hline Ataksi & 1 & 5 \\
\hline Hiperaktivite & 1 & 5 \\
\hline
\end{tabular}

${ }^{*}$ Bir hastada birden fazla bulgu vardı 
değişik zamanlarda çekilen EEG bulguları değerlendirildiğinde tümünde 1-3 Hz/sn diken yavaş dalga aktivitesi (Şekil 1) izlenirken, \%30'unda (altı hasta) biyoelektrik status epileptikus, \%20'sinde (dört hasta) 9-14 Hz/sn hızlı aktivite deşarjı, \%15'inde (üç hasta) bitemporal ve frontal diken-yavaş dalga aktivitesi, \%10'unda (iki hasta) çok sayıda diken deşarjları izlendi (Tablo 2).

Lennox-Gastaut sendromlu hastaların \%60'। (12 hasta) günde çok sayıda nöbet geçiriyordu. Dört (\%20) hastada nöbetler 6 ay-4 yıl arasında değişen sürelerde kontrol altına alındı (bir hasta 4 yll, bir hasta 3 yll, bir hasta 1 yll, bir hasta 6 ay süredir nöbetsiz). Hastaların nöbet sıklığı Tablo 2'de gösterildi. Günde

\begin{tabular}{|c|c|c|}
\hline Nöbet tipi & Sayı* & $\%$ \\
\hline Yaygın tonik & 16 & 80 \\
\hline Yaygın tonik klonik & 15 & 75 \\
\hline Atonik-drop atak & 12 & 60 \\
\hline Kısmi nöbetler & 8 & 40 \\
\hline Atipik absans & 7 & 35 \\
\hline Miyoklonik & 5 & 25 \\
\hline \multicolumn{3}{|l|}{ Nöbet sıklığı } \\
\hline Günde birden fazla nöbeti olan & 12 & 60 \\
\hline $1-3$ ayda $1-2$ kez nöbeti olan & 4 & 20 \\
\hline Nöbeti kontrol altına alınan & 4 & 20 \\
\hline \multicolumn{3}{|l|}{ EEG bulgusu } \\
\hline $1-3 \mathrm{~Hz} / \mathrm{sn}$ diken yavaş dalga aktivitesi & 20 & 100 \\
\hline Biyoelektrik status epileptikus & 6 & 30 \\
\hline Hızlı aktivite deşarjları (9-14 Hz/sn) & 4 & 20 \\
\hline $\begin{array}{l}\text { Bitemporal ve frontal } \\
\text { diken-yavaş dalga aktivitesi }\end{array}$ & 3 & 15 \\
\hline Çoklu diken deşarjı (6-7 Hz/sn) & 2 & 10 \\
\hline
\end{tabular}

* Bir hastada birden fazla bulgu

Tablo 3. Lennox-Gastaut sendromlu hastalarda kraniyal MRG bulguları $(n=19)$

\begin{tabular}{|l|c|c|}
\hline MRG bulguları* $^{*}$ & $\mathbf{n = 1 5}$ & $\%$ \\
\hline Normal & 4 & 25 \\
\hline Beyin atrofi & 7 & 35 \\
\hline $\begin{array}{l}\text { Kortikal displazi (pakigiri, polimikrogiri, } \\
\text { lizansefali, kolposefali) }\end{array}$ & 3 & 15 \\
\hline Perivantriküler lökomalasi & 3 & 15 \\
\hline Korpus kallozum disgenezisi & 3 & 15 \\
\hline Porensefali & 1 & 5 \\
\hline
\end{tabular}

* Bir hastada birden fazla bulgu vardı

MRG: Manyetik rezonans görüntüleme birden fazla nöbeti olan 12 hastanın 10'unda $(\% 83,3)$ infantil spazm öyküsü vardı ve nöbetler bir yaştan önce başlamıştı.

Kraniyal manyetik rezonans görüntüleme (MRG) bulgusu $15(\% 75)$ hastada vardı. Kraniyal manyetik rezonans görüntüleme bulguları yedi (\%35) hastada beyin atrofisi, üç (\%15) hastada kortikal displazi (inkomplet lizansefali, pakigiri, polimikrogiri, kolposefali), üç (\%15) hastada periventriküler lökomalasi (PVL), üç (\%15) hastada korpus kallozum disgenezisi ve bir $(\% 5)$ hastada poransefalik kist şeklinde idi (Tablo 3). Bir hastada kraniyal tomografide kafa içinde kanama saptandı. Kraniyal görüntülemesi normal olan dört (\%20) hastanın zeka durumu diğerlerine göre daha iyiydi ve desteksiz yürüyorlardı. Kraniyal MRG'si normal olan iki hastanın nöbetleri kontrol altında iken, ikisinin günde çok sayıda nöbeti vardı.

Hastaların hepsi çoklu antiepileptik tedavi alıyordu. En sık kullanılan antiepileptik ilaçlar sodyum valproat, klobazam, lamotrijin ve topiramattı. Sekiz (\%40) hastaya intravenöz gamaglobulin (IVIG) verildi. İntravenöz gamaglobulin tedavisi sonrasında beş $(\% 62,5)$ hastanın nöbetlerinin sayısında değişiklik olmazken, üç $(\% 37,5)$ hastada 2-6 ay süre ile \% 50 azaldı. Çoklu AEI kullanırken tedaviye klobazam, topiramat ve lamotrijịn eklenince hastaların nöbet sıklı̆ı değerlendirildi. Klobazam başlanan 15 hastanın altısında (\%40) nöbet sıklığı değişmedi, üç (\%20) hastada \%50 azaldı ve ortalama dört (19) ay sonra nöbetleri tekrar sıklaştı. Beş $(\% 33,3)$ hastada ortalama 5,5 (1-12) ay nöbetsizlik sağlandı. Topiramat alan

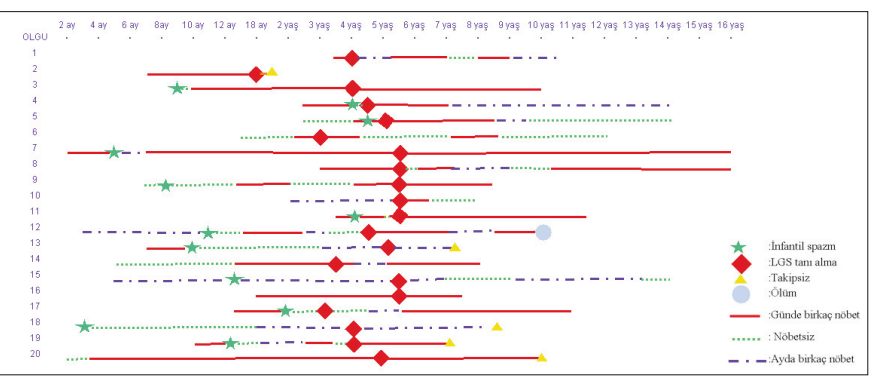

Şekil 1. EEG'de 1-3 Hz/sn diken-yavaş dalga aktivitesi

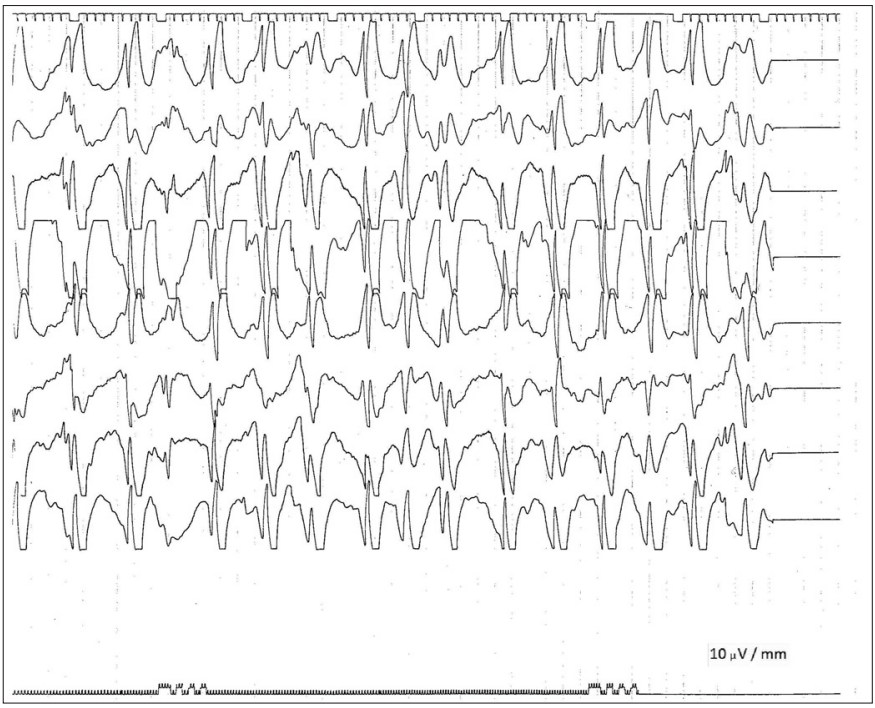

Şekil 2. Lennox-Gastaut sendromlu hastaların uzun süreli izlemi 


\begin{tabular}{|c|c|c|c|c|c|}
\hline \multirow[b]{2}{*}{ Antiepileptik Ilaçlar } & \multirow[b]{2}{*}{$\begin{array}{l}\text { Değişiklik yok } \\
\text { (Hasta sayısı) }\end{array}$} & \multirow[b]{2}{*}{$\begin{array}{l}\% 50 \text { azalma } \\
\text { (Hasta sayısı) }\end{array}$} & \multicolumn{2}{|c|}{ Nöbetlerin kesilmesi } & \multirow[b]{2}{*}{$\begin{array}{c}\text { Toplam } \\
\text { (Hasta sayısı) }\end{array}$} \\
\hline & & & Hasta sayısı & Nöbetsizlik süresi & \\
\hline IVIG & 5 & 3 & - & - & 8 \\
\hline Klobazam & 6 & 4 & 5 & $1-12$ ay & 15 \\
\hline Topiramat & 2 & 4 & 2 & $8 a y-2,5$ yıl & 8 \\
\hline Lamotrijin & 7 & 1 & 1 & 6 ay & 9 \\
\hline
\end{tabular}

IVIG: İntravenöz gamaglobülin

sekiz hastanın dördünde (\%50) nöbetler \%50 azaldı ve ikisi (\%25) 8 ay-2,5 yıl nöbetsiz kaldı. Lamotrijin alan dokuz hastanın yedisinde $(\% 77,8)$ nöbet sıklığı değişmedi ve bir (\%11) hastanın nöbeti \%50 azaldı. Bir (\%11) hastanın nöbetleri altı ay süre ile kontrol altına alındı (Tablo 4.).

Bir hastada sodyum valproata bağlı hiperamonyemi ve ansefalopati tablosu gelişti. Bir hasta sepsis, yaygın damar içi pıhtılaşma bozukluğu nedeniyle kaybedildi. Şekil 2'de hastaların uzun süreli izlemi gösterildi.

\section{Tartışma}

Çocukluk çağı epilepsilerinin yaklaşık \%10'unu oluşturan LGS 1-8 yaş arasında ortaya çıkar ve en sık 3-5 yaş arasında görülür $(3,8)$. Erkekler kızlardan daha fazla etkilenmektedir $(5,9)$. Bu çalışmada hastaların \%15'i 1-3 yaş, \%40' $3-5$ yaş, \%45'i ise 5-8 yaş arasında LGS tanısı almıştı ve erkek/kız oranı 1,9 idi. Bulgu veren LGS'de etiolojide doğum öncesi, doğum ve doğum sonrası hipoksi, MSS enfeksiyonları, MSS malformasyonları, nörokütanöz ve nörometabolik hastalıklar ve travma rol oynamaktadır $(3,4)$. Hastaların \%30'unda ise bir neden bulunamamaktadır (9). Bu çalısmada ise hastaların 19'unun (\%95) bulgusu vardı, biri (\%5) idiyopatikti. En sık saptanan etiolojik neden HIA ve kortikal displazi idi. Literatüre göre idiyopatik LGS yüzdesinin daha düşük olması hastaların geriye dönük olarak değerlendirilmesi ve HİA tanısının öyküyle konulmasından kaynaklanıyor olabilir. Sadece bir hasta idiyopatik LGS olduğu için bulgusu olan grup ile nöbet sıklığı ve seyir açısından karşılaştırma yapılamadı. Bulgusu olan ve idiyopatik LGS hastaların nöbet tipi ve sıklığı, EEG bulguları ve tedaviye yanıtları arasında belirgin bir fark olmadığı bildirilmektedir $(10,11)$.

Lennox-Gastaut sendromunun etiolojisinde daha çok beyin hasarı rol oynamakta, genetik etkenler ise daha az sıklıkta bildirilmektedir. Hastaların \%18-50'sinde infantil spazm öyküsü bulunmaktadır. İnfantil spazm sonrası gelişen LGS daha erken yaşta başlamakta, tonik nöbetler daha sık görülmektedir. Nöromotor gelişimi daha ağır etkilenmektedir (5). LennoxGastaut sendromu gelişme riski ketojenik diyet uygulanan, prednizolon veya ACTH verilen West sendromlu hastalarda daha düşük bulunurken, West sendromu tanı alma yaşı ve etioloji arasında ilişki saptanmadığı bildirilmektedir (12). Bu çalışmada hastaların \%60'ında infantil spazm öyküsü vardı ve infantil spazm öyküsü olan hastaların $\% 83,3$ 'ü günde çok sayıda nöbet geçiriyordu. Lennox-Gastaut sendromu gelişme yaşı infantil spazm öyküsü olmayanlardan farklı değildi.
Lennox-Gastaut sendromlu hastalarda değişik derecelerde zeka geriliği, davranış problemleri ve altta yatan nedene göre nörolojik bulgular ortaya çıkmaktadır. Mikrosefali, beyin felci, hipotoni, ataksi, piramidal bulgular ve yutma güçlüğü görülebilmektedir $(13,14)$. Beyin hasarı, dirençli nöbetler, sosyal uyaran eksikliği ve kullanılan antiepileptik ilaçların yan etkilerine bağlı olarak LGS'li hastalarda davranış problemleri, depresyon ve otistik bulgular sık görülmektedir (4). Bu çalışmada tüm hastalarda orta ya da ağır derecede zeka geriliği vardı. Nöbetleri daha geç başlayan ve nöbet öncesi nöromotor gelişimi normal olan hastaların zeka ve motor geriliği daha azdı. En sık görülen nörolojik bulgular konuşma bozukluğu, mikrosefali, hemiparezi, spastisite, yutma güçlüğü, ataksi ve nistagmus idi. Hastaların \%20'sinde otistik bulgular, \%10'unda sinirlilik ve \%5'inde ise hiperaktivite vardı. Nöropsikiyatrik bulguları olan hastaların hepsinde infantil spazm öyküsü vardı. West sendromunun otistik yelpazedeki bozukluk ile ilişkili olduğu bildirilmektedir $(15,16)$.

Bu çalışmada kraniyal MRG'de en sık beyin atrofisi, kortikal displazi, korpus kallozum disgenezisi, PVL ve porensefalik kist saptandı. Hastaların \%25"inde anormal MRG bulgusu yoktu. Çalışkan ve ark. (14) 68 LGS hastasında en sık saptanan kraniyal MRG bulgusunu beyin atrofisi olarak saptadılar. Goldsmith ve ark. (10) MR bulgularının nöbetler üzerine seyirde değeri olmadığını bildirdiler. Bu çalışmada kraniyal görüntülemenin nöbet sıklı̆̆ı üzerine etkisi saptanmadı. Ancak kraniyal görüntülemesi normal olan hastalarda zeka ve motor durum daha iyiydi.

Tonik, atonik, atipik absans nöbetler LGS'nin tipik nöbet tiplerini oluştururken miyoklonik, miyoklonik astatik, fokal nöbetler ve konvülzif olmayan status epileptikus da görülebilmektedir. En sık tonik ve atipik absans nöbetleri görülmektedir (17). Bu çalışmada da en sık görülen nöbet tipi yaygın tonik, yaygın tonik klonik ve atonik-drop atak idi. Atipik absans nöbetlerinin daha az sıklıkta görülmesinin nedeni ailelerin nöbetleri fark edememesinden kaynaklanıyor olabilir. İzlem süresince bir hastada iki kez olmak üzere toplam üç (\%15) hastada status epileptikus gelişmişti. Hastalarda çeşitli nöbet tiplerine göre farklı EEG bulguları görülebilmektedir. LennoxGastaut sendromunun tipik nöbetler arası EEG özelliği yaygın yavaş diken-dalga aktivitesidir. Uykuda $10-20 \mathrm{~Hz} / \mathrm{sn}$ hızlı ritm gözlenebilmektedir ancak LGS için özgün değildir. Hastaların $\% 50$ 'sinden fazlasında konvülzif olmayan status epileptikus görülmektedir (9). Bu hastaların \%30'unda konvülzif olmayan status epileptikus ve \%20'sinde hızlı aktivite deşarjları saptandı.

Lennox-Gastaut sendromunda çoklu AEİ kullanılmasına karşın nöbetler çoğu kez kontrol altına alınamamaktadır. Bu 
nedenle tedavide çok disiplinli bir yaklaşım gerekmektedir. Tedavinin amacı drop atak sayısını en aza indirmek, gündüz nöbetlerini azaltarak okul başarısını artırmak, nöbetlerin uzamasını ve konvülzif olmayan statusu önlemek olmalıdır (18). Çoklu AEI tedavisinin bazı nöbetleri artırması ve bilişsel, psikolojik yan etkileri nedeniyle çoklu tedaviden kaçınılmalıdır (4). Antiepileptik tedavi LGS etiolojisi ve nöbet tipine göre seçilmelidir. Genel olarak ilk seçenek valproik asit olmakta, lamotrijin, rufinamid, topiramat, klobazam, felbamat ve levetirasetam tedaviye eklenmektedir (18). LennoxGastaut sendromlu çocuklarda lamotrijin ve topiramat atonik ve tonik klonik nöbetlerde, valproik asit ise drop atak, atipik absans ve miyoklonik nöbetlerde etkin olmaktadır (19-21). Lennox-Gastaut sendromlu hastalarda yapılan çalışmalarda klobazaminin daha az sedasyon yaptığı, \%50'den fazla hastada nöbetleri \%50-100 arasında azalttığı, bir yıldan fazla kullanımdan sonra \%42 etkinliğinin devam ettiği ve hastaların \%72'sinde altı aydan fazla süre nöbetsizlik sağladığı bildirilmektedir $(22,23)$. İntravenöz gamaglobulin tedavisi ile LGS'li hastaların nöbetlerin azaldığı bildirilmektedir (24). Bu çalışmada en sık kullanılan AEl'ler sodyum valproat, klobazam, lamotrijin ve topiramat idi. İntravenöz gamaglobulin tedavisi alan üç $(\% 37,5)$ hastanın nöbeti $2-6$ ay süre ile $\% 50$ azaldı. Çoklu AEI kullanırken tedaviye klobazam, topiramat ve lamotrijin eklenince hastaların nöbet sıklığı değerlendirildiğinde, klobazam eklenen hastaların $\% 33,3$ 'ünde 1-12 ay, topiramat eklenen hastaların \%25'inde 8 ay-2,5 yıl, lamotrijin eklenenlerin ise \%11'inde altı ay süre ile nöbetsizlik sağlandı.

Zeka geriliği, davranış bozukluğu ve direçli nöbetler nedeniyle LGS'de seyir kötüdür (4). Bulgu vermesi, infantil spazm öyküsü, tanının üç yaşından önce konulması, sık nöbet ve status ataklarının olması ve EEG'de yaygın diken-yavaş dalga örüntüsünün devam etmesi kötü seyiri göstermektedir (9). Bu çalışmada ise infantil spazm öyküsü, nöbetlerin bir yaștan önce başlaması ve nöbet öncesi nöromotor gelişimin geri olması kötü seyir etmenleri olarak saptandı. Özellikle bulgu veren LGS'de altta yatan nedene göre nöbet direnci, nörolojik gerileme hızı ve şiddeti değişebilmektedir. Autry ve ark. (25) LGS'li hastalarda ölüm riskinin 14 kat arttığını bildirdiler. Nöbetlere bağlı beslenme ve yutma güçlüğü olabilmekte ve buna bağlı aspirasyon pnömonisi gelişebilmektedir (15). Bu çalışmada üç hastada yutma güçlüğü vardı. Bir hastada sodyum valproata bağlı hiperamonyemi ve ansefalopati tablosu gelişti, bir (\%5) hasta sepsis ve yaygın damar içi pıhtılaşma bozukluğu nedeniyle kaybedildi.

Sonuç olarak çocukluk çağı epileptik sendromu olan LGS'nin gerek dirençli nöbetler gerekse zeka işlevlerindeki bozulma nedeniyle seyri kötüdür. Altta yatan nedene ve dirençli nöbetlere bağlı olarak nörolojik gerileme olabilmekte ve hatta yatağa bağımlı hale gelebilmektedir. Var olan antiepileptiklerle çok az sayıda hastada nöbetler kontrol altına alınabildiği için yeni antiepileptiklere intiyaç duyulmaktadır. Tedavinin amacı nöbet sıkığı ve süresini azaltmak, yan etkileri nedeniyle çoklu AEI tedavisinden kaçınmak olmalıdır. Lennox-Gastaut sendromlu hastalar sadece tıbbi yönden değil aynı zamanda aileleriyle birlikte sosyal yönden de desteklenmeli ve ekip çalışması benimsenmelidir.

\section{Çıkar çatışması: Bildirilmemiştir.}

\section{Kaynaklar}

1. Niedermeyer E. Lennox-Gastaut syndrome. Clinical description and diagnosis. Adv Exp Med Biol 2002; 497: 61-75.

2. Gento P, Dravet C. Lennox-Gastaut syndrome. In: Engel, JR, Pedley TA, (eds). Epilepsy. A comprehensive textbook. Philadelphia: Wolters Kluver, Lippincott Williams and Wilkins, 2007: 2417-7.

3. Markand ON. Lennox-Gastauts syndrome (Childhood epileptic encephalopathy). J Clin Neurophysiol 2003; 20(6): 426-31.

4. Stafstrom CE. Update on the management of Lennox-Gastaut syndrome with a focus on rufinamide. Neuropsychiatr Dis Treat 2009; 5: 547-51.

5. Donat JF, Wright FS. Seizures in series: similarities between seizures of the West and Lennox-Gastaut syndromes. Epilepsia 1991; 32(4): 504-9.

6. Montelli TC, Mota NG, Peracoli MT, Torres EA, Rezkallah-Iwasso MT. Immunological disturbance in West and Lennox Gastaut syndromes. Arq Neuropsiquiatr 1984; 42: 132-9.

7. Crumrine PK. Lennox-Gastaut syndrome. J Child Neurol 2002; 17(Suppl 1): 70-5.

8. Trevathan E, Murphy CC, Yeargin-Allsopp M. Prevalence and descriptive epidemiology of Lennox-Gastaut syndrome among Atlanta children. Epilepsia 1997; 38(12): 1283-8.

9. van Rijckevorsel KV. Treatment of LGS: overview and recent findings. Neuropsychiatr Dis Treat 2008; 4(6): 1001-9.

10. Goldsmith IL, Zupanc ML, Buchhalter JR. Long-term seizure outcome in 74 patients with Lennox-Gastaut syndrome: effects of incorporating MRI head imaging in defining the cryptogenic subgroup. Epilepsia 2000; 41(4): 395-9.

11. Rantala H, Putkonen T. Occurence. Outcome and prognostic factors of infantile spasms and Lennox-Gastaut syndrome. Epilepsia 1999; 40: 286-7.

12. You SJ, Kim HD, Kang HC. Factors influencing the evolution of West syndrome to Lennox-Gastaut syndrome. Pediatr Neurol 2009; 41(2): 111-3.

13. Ogawa $K$, Kanemoto $K$, Ishii $Y$, et al. Long-term follow-up study of Lennox-Gastaut syndrome in patients with severe motor and intellectual disabilities: with special reference to the problem of dysphagia. Seizure 2001; 10(3): 197-202.

14. Çalışkan M, Yılmaz Y, Aydınlı N, Özmen M. Altmış sekiz LennoxGastaut sendromu vakasının özellikleri. Çocuk Sağlığı ve Hastalıkları Dergisi 1997; 40: 79-84.

15. Berg AT, Plioplys S, Tuchman R. Risk and correlates of autism spectrum disorder in children with epilepsy: a community-based study. J Child Neurol 2011; 26(5): 540-7.

16. Hançerli S, Çalışkan M, Mukaddes NM, Tatı B, Özmen M. West sendromunda otistik bozukluk. Turk Ped Arş 2011; 46: 68-74.

17. Ohtsuka Y, Amano R, Mizukawa M, Ohtahara S. Long-term prognosis of the Lennox-Gastaut syndrome. Jpn J Psychiatry Neurol 1990; 44(2): 257-64.

18. Ferrie CD, Patel A. Treatment of Lennox-Gastaut Syndrome (LGS). Eur J Paediatr Neurol 2009; 13(6): 493-504.

19. Motte J, Trevathan E, Arvidsson JF, Barrera MN, Mullens EL, Manasco P. Lamotrigine for generalized seizures associated with the LennoxGastaut syndrome. Lamictal Lennox-Gastaut Study Group. N Engl J Med 1997; 337(25): 1807-2.

20. Sachdeo RC, Glauser TA, Ritter F, Reife R, Lim P, Pledger G. A doubleblind, randomized trial of topiramate in Lennox-Gastaut syndrome. Topiramate YL Study Group. Neurology 1999; 52(9): 1882-7.

21. Schmidt D, Bourgeois B. A risk-benefit assessment of therapies for Lennox-Gastaut syndrome. Drug Saf 2000; 22(6): 467-7.

22. Conry JA, Ng YT, Paolicchi JM, et al. Clobazam in the treatment of Lennox-Gastaut syndrome. Epilepsia 2009; 50(5): 1158-66.

23. Ng Y, Collins SD. Clobazam. Neurotherapeutics 2007; 4(1): 138-44.

24. Illum N, Taudorf K, Heilmann C, et al. Intravenous immunoglobulin: a single-blind trial in children with Lennox-Gastaut syndrome. Neuropediatrics 1990; 21(2): 87-90.

25. Autry AR, Trevathan E, Van Naarden Braun K, Yeargin-Allsopp M. Increased risk of death among children with Lennox-Gastaut syndrome and infantile spasms. J Child Neurol 2010; 25(4): 441-7. 